We dedicate this paper to the memory of our coauthor Zachary Johnson.

Contributors: AWM had the original idea for the study, participated in interpreting data and writing the article, and is the guarantor for the study. PKP discussed core ideas, organised data analysis, and participated in interpreting data and writing the article. GB discussed core ideas and participated in interpreting data and writing the article. CL, FL, and ZJ participated in data retrieval and analysis. JW participated in interpreting data and writing the article.

Funding: None.

Competing interests: AWM, PKP, GB, and ZJ were authors of the previous article that suggested the present study hypothesis. ${ }^{2}$
1 Dale J, Green J, Reid F, Glucksman E, Higgs R. Primary care in the accident and emergency department. II: Comparison of general practitioners and hospital doctors. BMJ 1995;311:427-30.

2 Murphy AW, Bury G, Plunkett PK, Gibney D, Smith M, Mullan E, et al. A comparison of general practitioner and usual medical care in an urban accident and emergency department in terms of process, health status, and comparative costs. BMJ 1996;312:1135-42.

3 Murphy AW. Inappropriate attenders at accident and emergency departments. I: Definition, incidence and reasons for attendance. Fam Pract 1998;15:23-32.

4 Murphy AW. Inappropriate attenders at accident and emergency departments. II: Health service responses. Fam Pract 1998;15:33-7.

5 Raw M, McNeill A, West R. Smoking cessation: evidence based recommendations for the healthcare system. BMJ 1999;318:182-5.

(Accepted 13 January 2000)

\title{
Private funding of elective hospital treatment in England and Wales, 1997-8: national survey
}

\author{
Brian Williams, Pamela Whatmough, Janet McGill, Lesley Rushton
}

School of

Community Health

Sciences, University

of Nottingham,

Queens Medical

Centre, Nottingham

NG7 2UH

Brian Williams

professor of public

health medicine

Pamela

Whatmough

research associate

Janet McGill

research nurse

Medical Research

Council, Institute

for Environment

and Health,

University of

Leicester, Leicester

LE1 7DD

Lesley Rushton

head of epidemiology

Correspondence to:

B Williams

b.t.williams@

nottingham.ac.uk

BMJ 2000;320:904-5
The longest delays for admission to NHS hospitals have been reduced, and hospital throughput has increased in recent years. Whether the NHS has become more self sufficient in terms of elective treatment in hospital is not known. In 1981 the proportion of elective treatments purchased privately in England and Wales was 13.2\%, and in 1986 it was $14.8 \%{ }^{1}$ For $1992-3$ it was $14.1 \%$ (BT Williams, JP Nicholl, unpublished data). Using the same methods as in these previous studies we compared the volume and nature of elective hospital care funded publicly and privately in England and Wales in 1997-8.

\section{Methods and results}

Information on patients admitted as inpatients or day cases during sample periods in financial year 1997-8 were obtained from 215 of 221 acute independent hospitals with operating departments in England and Wales ${ }^{2}$; data obtained included the patient's clinical status, demographic information, and source of funding for the procedure. Numbers for the whole year were estimated by weighting the sample data according to the duration of sampling, the time of year, and the number of hospitals that did not respond; these numbers were validated as previously described. ${ }^{3}$ Extracts of the latest data (for 1996-7) were obtained from the Department of Health and the Welsh Information Agency's hospital episodes statistics for waiting lists and scheduled admissions for NHS and private patients admitted for non-psychiatric, non-maternity care. Data for first consultant episodes (98\% of all consultant episodes for elective patients and equivalent to the number of admissions) and data from independent hospitals were analysed using SPSS statistical software. Although these two sources of data were out of phase by a year, hospital episodes in the NHS for general and acute specialties rose only 2\% between 1996-7 and 1997-8 (NHS Executive, personal communication, 1999).

Altogether 739810 of 5094404 patients (14.5\%) had had private funding, and 591755 of 4415334 surgical patients (13.4\%) had had private funding (table). One in 10 private patients were treated in NHS hospitals, and $1 \%$ of NHS patients were treated in independent hospitals. Of the private admissions, $81 \%$ were funded by insurance and $18 \%$ were funded by the patient.

\section{Comment}

The proportion of elective treatments purchased privately has remained constant over nearly two decades. Although NHS patients and private patients receive a similar range of treatments the types of procedure differ proportionately. A higher than average proportion of patients pay for operations that relieve severe disability or discomfort-such as total replacement of the hip joint, which had a median NHS waiting time of 168 days in 1996-7, and lens operations for cataract (median waiting time 144 days)-and for those for which delay may increase the risk of dying, such as coronary artery operations (94 days). ${ }^{4}$ However, it is unlikely that all surgery performed privately would have been carried out on NHS patients. Procedures for which an above average proportion were funded privately included cosmetic operations for non-pathological conditions and gender reassignment. These have low priority in the NHS. The effectiveness of some other operations, such as middle ear drainage with grommets and stripping and ligation of varicose veins, is debatable, and some NHS authorities are refusing to fund them. Operations such as hysterectomy, prostatectomy, and cholecystectomy may be chosen in some instances instead of alternative, non-surgical forms of treatment. Lower thresholds for intervention apply to the use of some operations for private patients. ${ }^{5}$ Different clinical guidelines may also apply.

One of the functions of the Commission for Health Improvement is to ensure that clinical practice is evidence based. Its remit does not cover the private sector. Some health insurance companies already evaluate clinical indications for certain procedures before authorising them. Individual payers have no arbiter. The new national care standards commission, 
Number of elective treatments (excluding abortions) according to source of funding for residents of England and Wales, 1997-8

\begin{tabular}{|c|c|c|c|c|c|c|c|}
\hline \multirow[b]{2}{*}{ Operation or procedure } & \multicolumn{3}{|c|}{ Independent hospitals } & \multicolumn{3}{|c|}{ NHS hospitals } & \multirow{2}{*}{$\begin{array}{l}\% \text { privately } \\
\text { funded }\end{array}$} \\
\hline & Private & NHS & Total $^{*}$ & Private & NHS & Total & \\
\hline \multicolumn{8}{|l|}{ Eyes and ear, nose, and throat } \\
\hline Lens operations & 29159 & 3921 & 33218 & 4817 & 168282 & 173099 & 16.5 \\
\hline Other eye operations & 8572 & 270 & 8899 & 2652 & 138295 & 140947 & 7.5 \\
\hline Tonsillectomy and adenoidectomy & 11223 & 1730 & 13036 & 604 & 86098 & 86702 & 11.9 \\
\hline Drainage of middle ear & 10413 & 425 & 10872 & 390 & 52649 & 53039 & 16.9 \\
\hline Other ear, nose, and throat & 23540 & 1964 & 25700 & 2500 & 186857 & 189357 & 12.1 \\
\hline Dental operations & 20184 & 733 & 21186 & 753 & 153380 & 154133 & 11.9 \\
\hline \multicolumn{8}{|l|}{ Heart or blood vessels } \\
\hline Operations on coronary arteries & 4369 & 445 & 4843 & 1113 & 21205 & 22318 & 20.2 \\
\hline All other heart operations & 10540 & 583 & 11162 & 2805 & 80673 & 83478 & 14.1 \\
\hline Ligation or stripping of varicose veins & 12782 & 1888 & 15058 & 505 & 48340 & 48845 & 20.8 \\
\hline \multicolumn{8}{|l|}{ Gastrointestinal tract } \\
\hline Cholecystectomy & 6022 & 336 & 6390 & 441 & 30316 & 30757 & 17.4 \\
\hline Other major intra-abdominal operations & 6651 & 33 & 6684 & 1359 & 53389 & 54748 & 13.0 \\
\hline Diagnostic or therapeutic endoscopy of gastrointestinal tract & 62655 & 3079 & 65995 & 6693 & 524993 & 531686 & 11.6 \\
\hline Abdominal hernia repair & 20424 & 1398 & 21973 & 1104 & 80633 & 81737 & 20.8 \\
\hline Haemorrhoidectomy and other anal or perianal operations & 8946 & 634 & 9648 & 654 & 52414 & 53068 & 15.3 \\
\hline \multicolumn{8}{|l|}{ Operations for men } \\
\hline Prostatectomy & 6080 & 430 & 6544 & 571 & 39524 & 40095 & 14.3 \\
\hline Vasectomy & 2384 & 1874 & 4310 & 190 & 36913 & 37103 & 6.2 \\
\hline Circumcision & 3250 & 90 & 3374 & 281 & 24372 & 24653 & 12.6 \\
\hline \multicolumn{8}{|l|}{ Gynaecological } \\
\hline Dilatation and curettage & 3838 & 100 & 3938 & 332 & 44213 & 44545 & 8.6 \\
\hline All hysterectomy & 10320 & 562 & 11018 & 631 & 59223 & 59854 & 15.5 \\
\hline Repair prolapse of vagina or uterus & 5198 & 107 & 5305 & 262 & 22219 & 22481 & 19.7 \\
\hline Other gynaecological & 42052 & 917 & 43177 & 2443 & 197356 & 199799 & 18.3 \\
\hline Division, ligation, occlusion of oviducts & 469 & 449 & 918 & 195 & 47432 & 47627 & 1.4 \\
\hline \multicolumn{8}{|l|}{ Breast } \\
\hline Total excision of breast & 2051 & 96 & 2147 & 126 & 13164 & 13290 & 14.1 \\
\hline Partial excision of breast & 7116 & 456 & 7572 & 466 & 34983 & 35449 & 17.6 \\
\hline \multicolumn{8}{|l|}{ Orthopaedic } \\
\hline Total replacement of hip joint & 9571 & 1655 & 11299 & 1136 & 35239 & 36375 & 22.5 \\
\hline Total replacement of knee joint & 5041 & 924 & 5965 & 419 & 25960 & 26379 & 16.9 \\
\hline Other orthopaedic operations & 36362 & 2146 & 38833 & 3330 & 197058 & 200388 & 16.6 \\
\hline Diagnostic or therapeutic endoscopy of joint & 32026 & 2774 & 35287 & 1229 & 78827 & 80056 & 28.8 \\
\hline \multicolumn{8}{|l|}{ Miscellaneous } \\
\hline Cosmetic operations & 23165 & 219 & 23663 & 683 & 37414 & 38097 & 38.6 \\
\hline Gender reassignment & 104 & 0 & 104 & 6 & 46 & 52 & 70.5 \\
\hline Removal of lesion of skin & 19406 & 1349 & 21122 & 1139 & 169764 & 170903 & 10.7 \\
\hline All other operations or procedures & 93003 & 5624 & 99429 & 13285 & 1003960 & 1017245 & 9.5 \\
\hline Type of operation not known & 1001 & 93 & 1094 & 724 & 36543 & 37267 & 4.5 \\
\hline Total operations or procedures & 537917 & 37304 & 579762 & 53838 & 3781734 & 3835572 & 13.4 \\
\hline $\begin{array}{l}\text { No operation or procedure (includes patients treated } \\
\text { medically) }\end{array}$ & 131381 & 4638 & 136350 & 16674 & 526046 & 542720 & 21.8 \\
\hline Total (surgical and medical) & 669298 & 41942 & 716112 & 70512 & 4307780 & 4378292 & 14.5 \\
\hline
\end{tabular}

*Includes cases in which method of funding is not known.

which will regulate the private sector under the Care Standards Bill, may eventually need to embrace the task of ensuring the clinical relevance of procedures.

Contributors: BW initiated the study and with LR, PW, and JM performed the analyses and drafted the paper. LR performed the sampling and weighting procedures. All authors discussed the main issues, interpreted the data, and edited the draft. BW is the guarantor for the study.

Funding: The Association of British Insurers and the Independent Healthcare Association. Competing interests: None declared.

1 Nicholl JP, Beeby NR, Williams BT. The role of the private sector in elec tive surgery in England and Wales, 1986. BMJ 1989;298:243-7.

2 Independent Healthcare Association. Directory of independent hospitals and health services, 1996. London: Churchill Livingstone, 1996.

3 Williams BT, Nicholl JP. Patient characteristics and clinical caseload of short stay independent hospitals in England and Wales, 1992-3. BMJ 1994;308:1699-1701.

4 Plomp J, Redekop WK, Dekker FW, van Geldorp TR, Haalebos MMP, Jambroes B, et al. Death on the waiting list for cardiac surgery in the Netherlands in 1994 and 1995. Heart 1999;81:593-7.
5 Dawson J, Fitzpatrick R, Gundle R, Murray D. Provision of primary tota hip replacement surgery. Lancet 1999;353:2161.

(Accepted 10 February 2000)

\section{Endpiece \\ Doctors are just people}

Doctors make many phone calls, talk to many people. Doctors look out of their front windows, doctors frown, doctors show nervousness, doctors have things on their mind and show the strain. Doctors are just people, born to sorrow, fighting the long grim fight like the rest of us.

Raymond Chandler, The Lady in the Lake. London: Picador, 1983

Submitted by David Stone, consultant cardiologist, Papworth Everard, Cambridgeshire 